\title{
POTENSI KULIT KOPI SEBAGAI BAHAN BAKU PUPUK KOMPOS DI PROPINSI BENGKULU
}

\section{THE EXPERIMEN OF COFFEE FOR SKIN POTENTIAL RAW MATERIAL COMPOST IN BENGKULU PROVINCE}

\author{
Afrizon \\ Balai Pengkajian Teknologi Pertanian Bengkulu
}

\begin{abstract}
ABSTRAK
Penelitian dengan judul Potensi Kulit kopi Sebagai Bahan Baku Pupuk Kompos di Propinsi Bengkulu dilaksanakan di Laboratorium rumah kaca BPTP Bengkulu. Tujuan dari penelitian adalah 1) Menguji limbah kulit kopi menjadi pupuk kompos dalam upaya melestarikan lingkungan hidup, 2) Mengetahui potensi limbah kulit kopi sebagai bahan baku pupuk kompos di Propinsi Bengkulu. Dalam pembuatan kompos menggunakan rancangan acak lengkap (RAL) dengan 6 perlakuan dan 3 ulangan. Perlakuannya adalah : a) $70 \%$ limbah kopi $+20 \%$ Ppk kandang $+10 \%$ Dedak padi + EM4 + gula, b) $80 \%$ limbah kopi $+10 \%$ Ppk kandang + $10 \%$ Dedak padi + EM4 + gula, c) $80 \%$ limbah kopi $+20 \%$ Ppk kandang + EM4 + gula, d) $80 \%$ limbah kopi $+20 \%$ Pupuk kandang + EM4, e) $80 \%$ limbah kopi $+10 \%$ ppk kandang + $10 \%$ Dedak padi, f) $80 \%$ limbah kopi $+20 \%$ ppk kandang. Sedangkan untuk melihat potensi limbah kulit kopi dengan menghimpun data primer dan sekunder yang terkait dengan komoditas kopi yang mencakup luas pertanaman dan produktifitas di setiap kabupaten di propinsi Bengkulu. Data yang dihimpun adalah Prosentase limbah kulit kopi tiap $100 \mathrm{~g}$, luas pertanaman kopi setiap kabupaten, kandungan $\mathrm{N}, \mathrm{P}, \mathrm{K}$ dan $\mathrm{C}$ organik. Hasil penelitian menunjukan pembuatan kompos dengan waktu selama 4 minggu telah memberikan kematangan pupuk yang diindikasikan dengan nilai $\mathrm{C} / \mathrm{N}$ antara 9,75-15,99. Komposisi $80 \%$ limbah kulit kopi $+10 \%$ Pupuk kandang $+10 \%$ dedak padi memberikan pupuk kompos terbaik. Kompos dari bahan limbah kulit kopi memiliki kandungan nutrient sesuai dengan standar SNI 19-7030-2004 tentang standar kualitas kompos. Panen buah kopi kering giling menghasilkan 51,2 \% limbah kulit kopi dengan potensi sebesar 30.222 ton/tahun. setara dengan 738,323 ton $\mathrm{N} /$ th. Hal ini identik dengan mensubtitusi dengan kesetaraan nilai Urea $(46 \% \mathrm{~N})$ sebesar 339,628 ton/th. setara dengan 86,434 ton P205/th. Hal ini identik mensubtitusi dengan kesetaraan nilai superphos (SP-36) sebesar 31,116 ton/th setara dengan $876,438 \mathrm{~kg} \mathrm{~K} 2 \mathrm{O} / \mathrm{th}$ atau identik mensubtitusi $\mathrm{KCl}(60 \%)$ sebesar 525,862 ton/tahun.
\end{abstract}

Kata Kunci : kulit kopi, kompos, potensi

\section{ABSTRACT}

The experimen of Coffee For Skin Potential Raw Material Compost in Bengkulu Province was conducted from March to June 2010 in the laboratory greenhouse BPTP Bengkulu. The purpose of this study are 1) Testing coffee leather waste into compost in an effort to preserve the environment, 2) Determine the potential of waste as raw material for leather coffee fertilizer in Bengkulu Province. In the manufacture of compost using a completely randomized design (CRD) with 6 treatments and 3 replications. The treatments were: a) $70 \%$ waste + $20 \% \mathrm{KDP}$ coffee cage $+10 \%$ rice bran + EM4 + sugar, b) $80 \%$ waste $+10 \% \mathrm{KDP}$ coffee 
cage $+10 \%$ rice bran + EM4 + sugar, c) $80 \%$ waste coffee $+20 \%$ KDP cage + EM4 + sugar, d) $80 \%+20 \%$ of coffee waste Manure + EM4, e) $80 \%$ waste $+10 \%$ KDP coffee cage $+10 \%$ rice bran, $f$ ) $80 \%$ waste +20 copies $\%$ KDP cage. As for seeing the potential of coffee leather waste by gathering primary and secondary data related to commodities which includes the area planted with coffee and productivity in every district in Bengkulu province. The data collected is the percentage of skin waste of coffee per $100 \mathrm{~g}$, area planted with coffee every district, the content of $N, P, K$ and $C$ organic. The research shows that compost with time for 4 weeks has given the maturity of fertilizer as indicated by the value of $C / N$ between 9.75 to 15.99 . The composition of $80 \%$ waste $+10 \%$ coffee hull Manure $+10 \%$ rice bran provides the best compost. Compost made from leather wastes contain nutrients coffee in accordance with ISO standards 19-7030-2004 about compost quality standards. Dried coffee fruit harvest yield 51.2\% milled coffee leather waste with a potential of 30,222 tons / year. equivalent to 738.323 tons $N / y r$. This is identical to substitute with an equal amount of urea $(46 \% N)$ of 339.628 tons / year. equivalent to 86.434 tons P205/th. This is identical to substitute with an equal value superphos (SP-36) amounted to 31.116 tons / yr, equivalent to

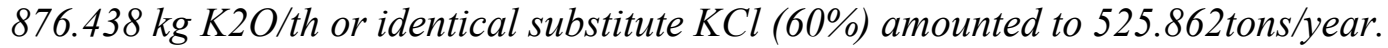

Keywords : coffee leather waste, compost, potential

\section{PENDAHULUAN}

Pupuk merupakan kebutuhan dasar dalam system produksi pertanian. Pupuk an organik yang selama ini sebagai salah satu kebutuhan dasar dalam mendukung produktifitas hasil pertanian ketersediaannya saat ini sangat terbatas akibat meningkatnya permintaan ditingkat petani. Disamping itu kemampuan petani untuk membeli juga sangat terbatas. Kondisi ini berimbas kapada penurunan produktifitas lahan dan produksi berbagai komoditas pertanian secara nasional. Salah satu alternatif untuk mempertahankan produksi pertanian dan menyelamatkan keberlanjutan penggunaan lahan pertanian secara lestari adalah dengan mengurangi input dari bahan kimia dan beralih kepada pemakaian pupuk kompos yang berasal dari limbah hasil pertanian (Abdoellah, 1993).

Strategi pengelolaan lahan pertanian pada masa mendatang seyogianya tidak hanya mengutamakan kepentingan ekonomi yang hanya berpola pikir jangka pendek, namun harus memikirkan dimensi ekologi (pengelolaan berwawasan lingkungan), sosial budaya dan kelembagaan agar tercipta suatu pengelolaan lahan pertanian yang berkelanjutan.

Limbah kulit kopi merupakan salah satu limbah padat yang banyak terdapat di sentra produksi kopi di Propinsi Bengkulu. Limbah organik ini belum banyak dimanfaatkan bagi keperluan pertanian dan dibuang begitu saja di lokasi penggilingan 
biji kopi, sehingga menjadi salah satu sumber pencemaran di daerah sekitarnya. Sebagai bahan organik yang mempunyai kandungan unsur hara, maka limbah kopi kalau dilakukan sedikit sentuhan teknologi akan mempunyai banyak manfaat baik dari aspek ekonomi, lingkungan, tanah maupun tanaman.

\section{METODE PENELITIAN}

Analisis Unsur hara dilakukan di Laboratorium tanah BPTP Bengkulu. Bahan dan alat yang digunakan adalah limbah kulit kopi, dedak padi, pupuk kandang, bioaktifator, gula pasir/gula merah, air, karung plastik, terpal plastik, cangkul dan Timbangan.

Secara umum prosedur pembuatan adalah sebagai berikut : Bio aktifator, air dan gula diaduk merata (perbandingan $1: 15: 0,5$ ). Limbah kopi, pupuk kandang dan Dedak padi dicampur sampai rata sesuai perlakuan setiap formulasi disiram dengan larutan EM4, air dan gula (larutan nomor 1). kemudian diaduk agar larutan merata pada semua campuran

Setiap satu minggu dilakukan pembalikan campuran bahan organik agar aerasi udara dalam kompos dapat berjalan dengan baik dan menghindari terjadinya proses an aerob. Kalau campuran terlalu kering lakukan penyiraman secukupnya dengan air bersih pakai sprayer. Setelah 4 minggu kompos siap dibongkar. Kompos yang sudah terbentuk terlihat berwarna kehitamhitaman, struktur remah dan tidak panas. Satu minggu setelah selesai proses pembuatan kompos dilakukan analisa.

Untuk mengetahui potensi limbah kulit kopi sebagai bahan baku pupuk kompos di Propinsi Bengkulu dilakukan dengan menghimpun data sekunder yang meliputi luas dan produksi kopi di semua Kabupaten wilayah Propinsi Bengkulu. Selanjutnya dengan data yang didapat ditabulasi untuk melihat potensi limbah kulit kopi sebagai bahan baku pupuk kompos di Propinsi Bengkulu.

Peubah yang diamati ialah data primer dan data sekunder. Data primer yang diambil meliputi data persentase ampas pada satuan berat tertentu, kandungan Nitrogen $(\mathrm{N})$, Phospor $(\mathrm{P}), \mathrm{C} / \mathrm{N}$ ratio dan Bahan Organik dari pupuk kompos yang dibuat. Data sekunder meliputi distribusi daerah penghasil kopi, produksi kopi pada daerah setiap Kabupaten, produksi kopi se Propinsi Bengkulu. Variabel yang akan diamati dalam penelitian ini adalah Pesentase limbah/ampas biji kopi setiap $100 \mathrm{~kg}$, Luas pertanaman kopi setiap Kabupatendan 
Propinsi Bengkulu dan N,P,K, C- organik kompos.

Dalam penelitian ini menggunakan Rancangan Acak Lengkap (RAL) dengan 6 macam perlakuan (formulasi) dan 3 kali ulangan. Formulasi terdiri dari bahan dasar limbah kulit kopi yang dikombinasikan dengan bahan organik lain dan bio aktifator (EM4). Keenam formulasi tersebut adalah :
$70 \%$ limbah kopi $+20 \%$ Ppk kandang + $10 \%$ Dedak padi + EM4 + gula, $80 \%$ limbah kopi $+10 \%$ Ppk kandang $+10 \%$ Dedak padi + EM4 + gula, $80 \%$ limbah kopi $+20 \%$ Ppk kandang + EM4 + gula, $80 \%$ limbah kopi $+20 \%$ Pupuk kandang + EM4 , $80 \%$ limbah kopi $+10 \%$ ppk kandang $+10 \%$ Dedak padi dan $80 \%$ limbah kopi $+20 \%$ ppk kandang.

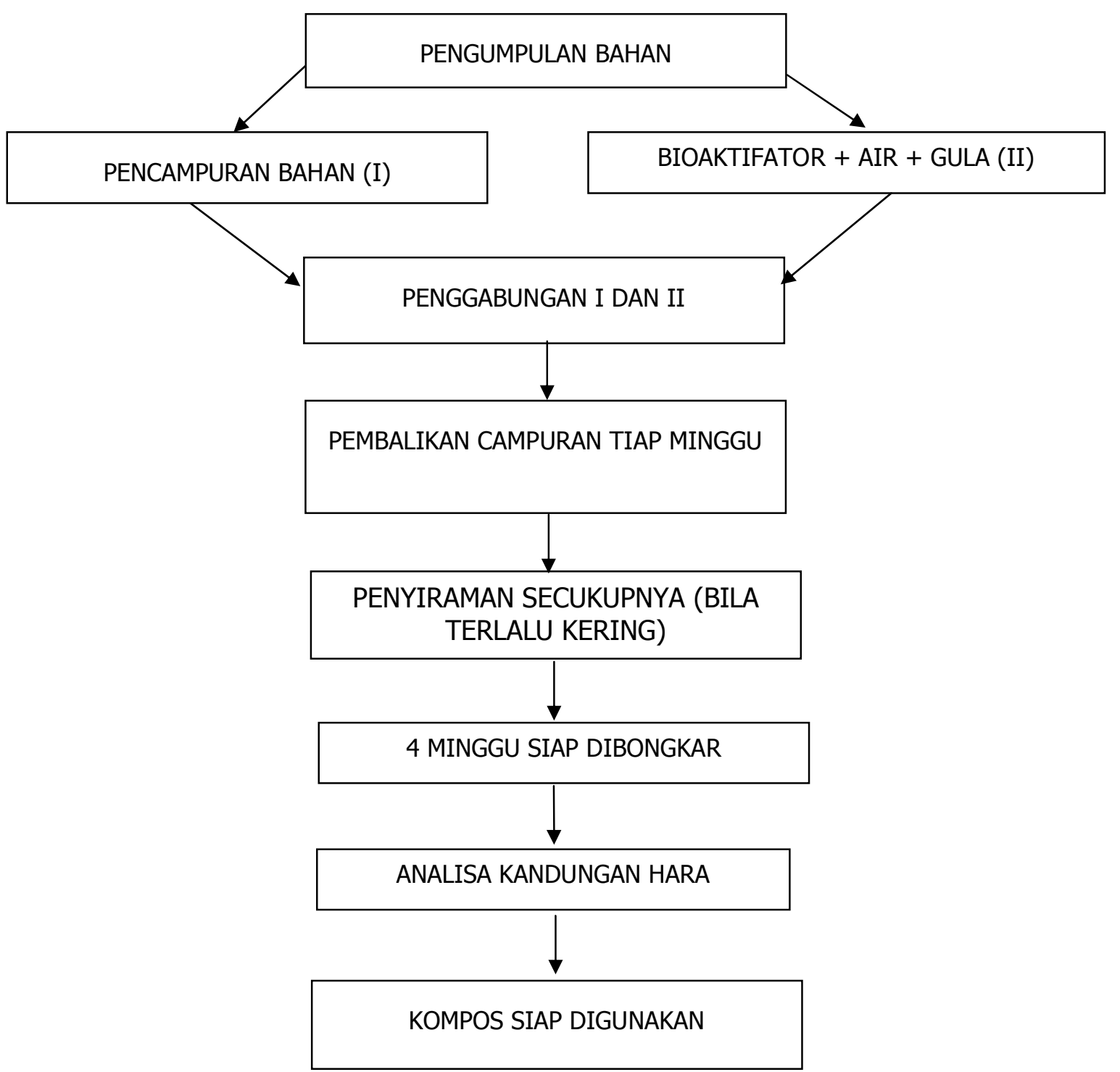

Gambar 1. Alur Prosedur Pembuatan Kompos 
Data hasil pengamatan N, P dan K kompos yang diperoleh dianalisis dengan menggunakan analisis keragaman pada taraf $5 \%$ dan apabila terdapat beda nyata akan dilanjutkan dengan uji DMRT (Duncans Multiple Range Test).

\section{HASIL DAN PEMBAHASAN}

\section{Hasil analisis kompos}

Dari Tabel 1 terlihat bahwa nilai $\mathrm{C} / \mathrm{N}$ dari semua formulasi pupuk kompos yang dibuat pada 4 minggu proses pengomposan nilai $\mathrm{C} / \mathrm{N}$ semuanya berkisar antara 9,75-15,99 (dibawah angka $20 \%$ ). Hal ini mengindikasikan bahwa pada proses dekomposisi bahan organik pertanian dari limbah kulit kopi pada semua perlakuan dapat dinyatakan baik menurut standart kualitas kompos SNI 2004. Namun yang bisa langsung diserap tanaman setelah diaplikasi harus mendekati atau sama dengan nilai $\mathrm{C} / \mathrm{N}$ tanah yaitu $10-12 \%$ (Isroi, 2008).

Berdasarkan tabel 2 pupuk kompos dalam penelitian ini secara umum telah berada di kisaran nilai standar yang telah ditetapkan oleh SNI tahun 2004 dan aman untuk digunakan pada tanaman dan lingkungan. Bila kandungan nilai $\mathrm{N}$ kompos pada masing-masing perlakuan di bandingkan dengan kandungan nilai $\mathrm{N}$ pada pupuk kandang padat yang sebesar $1 \% \mathrm{~N}$ yang berasal dari kotoran ternak ayam, kotoran ternak sapi mengandung $0,40 \% \quad \mathrm{~N}$ dan kotoran ternak kambing terdiri dari $0,75 \%$ N (Tisdale dan Nelson, 1975), tentunya nilai $\mathrm{N}$ pada masing-masing perlakuan dalam penelitian ini masih lebih baik. Hal ini diduga dari sususan komposisi bahan pembuat kompos dimana limbah kulit kopi memiliki proporsi yang terbesar dibanding bahan lainnya (70-80\%), sementara disisi lain $\mathrm{N}$ kulit kopi juga memiliki kadar yang relatif tinggi yaitu sebesar $2,98 \% \mathrm{~N}$.

Berdasarkan data kandungan nilai $\mathrm{P}_{2} \mathrm{O}_{5}(\mathrm{P})$ kompos (Tabel 3) memperlihatkan rata-rata kandungan nilai $\mathrm{P}$ tertinggi pada perlakuan D dan E masing-masing sebesar 0,286\% dan kemudian diikuti oleh perlakuan C sebesar 0,273\%, lalu perlakuan A dan B yang masing-masing sebesar $0,253 \%$, dan kemudian terendah pada perlakuan $\mathrm{F}$ sebesar 0,213\%. Hasil uji kandungan hara kompos organik menunjukkan kandungan $\mathrm{P}$ dengan kisaran 0,213\% (F) hingga 0,286\% (D) yang melebihi standar yang dikeluarkan SNI: 19-7030-2004 tentang standar kualitas kompos dengan kandungan nilai $\mathrm{P}$ minimal $0,10 \%$.. Oleh karena itu kadar $\mathrm{P}$ yang dihasilkan pada kompos dalam penelitian ini telah memenuhi standar minimal berdasarkan SNI (min 0,10\%) baik. 
Tabel 1. Analisis C/N pada Formulasi Pupuk Kompos

\begin{tabular}{lllll}
\hline Perlakuan & C Organik & Nitrogen & C/N & Bahan Organik \\
\hline A & 22,05 & 2,05 & 10,75 & 38,01 \\
B & 26,35 & 1,92 & 13,72 & 45,42 \\
C & 28,10 & 2,01 & 13,98 & 48,44 \\
D & 24,20 & 1,98 & 12,22 & 41,42 \\
E & 17,75 & 1,82 & 9,75 & 30,61 \\
F & 29,75 & 1,86 & 15,99 & 51,29 \\
\hline
\end{tabular}

Tabel 2. Perbedaan Perlakuan terhadap Kandungan Nitrogen (N) Kompos

\begin{tabular}{lll}
\hline Perlakuan & Rataan & DMRT \\
\hline E & 2,443 & a \\
C & 2,323 & ab \\
D & 1,963 & abc \\
B & 1,920 & abc \\
A & 1,580 & bc \\
F & 1,470 & c
\end{tabular}

Keterangan : Angka angka yang diikuti oleh huruf yang sama menunjukan tidak berbeda nyata.

Tabel 3. Perbedaan Perlakuan terhadap Kandungan Pospor (P) Kompos

\begin{tabular}{lll}
\hline Perlakuan & Rataan & DMRT \\
\hline E & 0,286 & A \\
D & 0,286 & a \\
C & 0,273 & a \\
A & 0,253 & ab \\
B & 0,253 & ab \\
F & 0,213 & b
\end{tabular}

Keterangan : Angka angka yang diikuti oleh huruf yang sama menunjukan tidak berbeda nyata. 
Tabel 4. Perbedaan Perlakuan terhadap Kandungan Kalium (K) Kompos

\begin{tabular}{lll}
\hline Perlakuan & Rataan & DMRT \\
\hline E & 2,90 & A \\
A & 2,116 & b \\
C & 1,986 & b \\
D & 1,606 & bc \\
B & 1,423 & cd \\
F & 0,916 & d \\
\hline
\end{tabular}

Keterangan : Angka angka yang diikuti oleh huruf yang sama menunjukan tidak berbeda nyata.

Hasil uji kandungan hara kompos organik menunjukkan kandungan $\mathrm{K}$ dengan kisaran 0,916\% (F) hingga 2,9\% (D). Hasil ini telah berada di atas nilai minimal berdasarkan standar yang dikeluarkan SNI: 19-70302004 tentang standar kualitas kompos dengan kandungan nilai $\mathrm{K}$ minimal 0,20\%. Bila dilihat bahan penyusun komposnya, kulit kopi sangat memberi kontribusi terbesar dimana kulit kopi memiliki kandungan nilai $\mathrm{K}$ sebesar 2,26\% (Anonim, 2010) yang tersusun atas $70-80 \%$ komposisi bahan penyusun kompos bila dibandingkan dengan pupuk kandang yang hanya memiliki kandungan nilai $\mathrm{K}$ sebesar $0,40 \%$ $\mathrm{K}_{2} \mathrm{O}$ yang berasal dari kotoran ayam, atau $0,10 \mathrm{~K}_{2} \mathrm{O}$ yang berasal dari ternak sapi atau 0,45 K2O yang berasal dari ternak kambing (Tisdale dan Nelson, 1975). Oleh karenanya dalam hasil untuk kandungan nilai $\mathrm{K}$ pada semua perlakuan dalam penelitian ini relatif masih lebih baik bila dibandingkan dengan kandungan nilai $\mathrm{K}$ pupuk kandang $(0,10 \%$ $0,45 \%$ )

Secara keseluruhan, kadar unsur hara N, P dan $\mathrm{K}$ dalam kompos dari hasil penelitian dapat dilihat pada gambar 2. Dari Gambar 2 dapat dilihat bahwa kadar nilai N, P, K tertinggi di peroleh pada perlakauan E (80\% limbah kulit kopi $+10 \%$ pupuk kandang + $10 \%$ dedak padi ) dan terendah di peroleh oelh perlakuan F $(80 \%$ limbah kulit kopi + 20\% pupuk kandang). Pelakuan E nilai N, $\mathrm{P}, \mathrm{K}$ yang di hasilkan masing-masing adalah $2,443 \% \mathrm{~N}, 0,286 \% \mathrm{P}_{2} \mathrm{O}_{5}$, dan 2,9\% $\mathrm{K}_{2} \mathrm{O}$. Sedangkan Nilai N, $\mathrm{P}, \mathrm{K}$ yang di peroleh oleh perlakuan $\mathrm{F}$ masing-masing adalah $1,47 \% \mathrm{~N}, 0,213 \% \mathrm{P}_{2} \mathrm{O}_{5}$, dan $0,916 \%$ $\mathrm{K}_{2} \mathrm{O}$.

Secara umum dalam Tabel 5 terlihat kualitas kompos yang dihasilkan oleh masing-masing perlakuan dalam pelitian ini 
dapat dikatakan baik karena nilai kadar $\mathrm{C} / \mathrm{N}, \mathrm{N}, \mathrm{P}$ dan $\mathrm{K}$ yang dihasilkan masih memenuhi standar SNI: 19-7030-2004.

Menurut Puslitkoka (2008) untuk memperoleh biji kopi yang bermutu baik diharuskan panen pada saat matang fisiologis (petik merah). Dari Tabel 8 terlihat bahwa dari 5 kali pengamatan terhadap penggilingan $100 \mathrm{~kg}$ buah kopi kering giling, maka yang keluar menjadi biji kopi adalah berkisar antara $44-54,5 \mathrm{~kg}$ (rata-rata $48,8 \mathrm{~kg}$ ) dan yang menjadi limbah kulit kopi lebih berat yang berkisar antara $45,5-56 \mathrm{~kg}$ (rata-rata $51,2 \mathrm{~kg}$ )

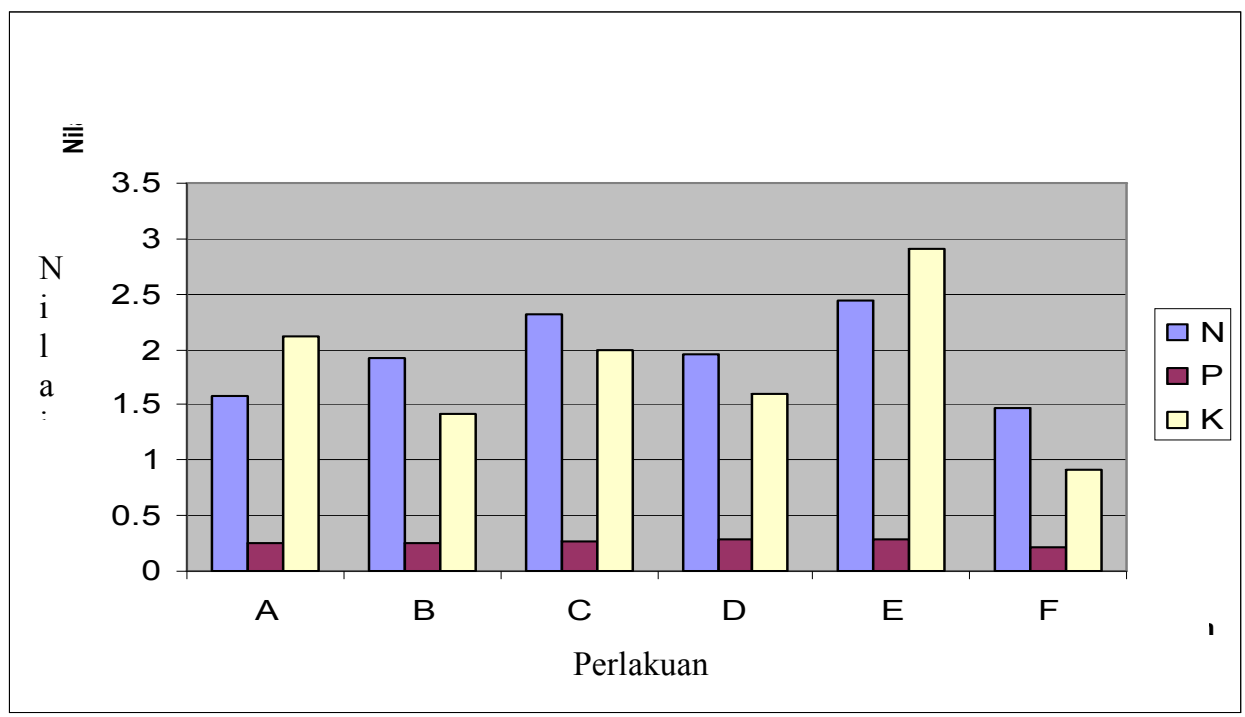

Gambar 2. Kadar NPK dari masing-masing perlakuan

Tabel 5. Kandungan Unsur Hara Kompos Kulit Kopi (\%)

\begin{tabular}{cccc}
\hline Perlakuan & \multicolumn{3}{c}{ Kandungan hara } \\
\cline { 2 - 4 } & $\mathrm{N}$ & $\mathrm{P} 205$ & $\mathrm{~K} 20$ \\
\hline $\mathrm{A}$ & 1,58 & 0,253 & 2,116 \\
$\mathrm{~B}$ & 1,92 & 0,253 & 1,423 \\
$\mathrm{C}$ & 2,323 & 0,273 & 1,986 \\
$\mathrm{D}$ & 1,963 & 0,286 & 1,606 \\
$\mathrm{E}$ & 2,443 & 0,286 & 2,900 \\
$\mathrm{~F}$ & 1,47 & 0,213 & 0,916 \\
\hline
\end{tabular}


Tabel 6. Luas Pertanaman Kopi Rakyat di Propinsi Bengkulu (ha)

\begin{tabular}{llrrrl}
\hline \multirow{2}{*}{ No } & \multirow{2}{*}{ Kabupaten } & \multicolumn{3}{c}{ Luas Pertanaman } & \multirow{2}{*}{ Jumlah } \\
\cline { 3 - 4 } & & \multicolumn{1}{c}{ TBM } & T. Tua & TM & \\
\hline 1 & Muko Muko & 138,00 & 169,00 & 1.373 & 1.680 \\
2 & Bengkulu Utara & 1.409 & 3.212 & 13.945 & 18.606 \\
3 & Kota Bengkulu & 1,00 & 0,00 & 20,00 & 21,00 \\
4 & Seluma & 743,00 & 2.601 & 13.206 & 16.550 \\
5 & Bengkulu Selatan & 326,00 & 84,00 & 2.688 & 3.098 \\
6 & Kaur & 1.363 & 1.701 & 4.921 & 7.985 \\
7 & Lebong & 1.750 & 1.015 & 5.084 & 7.849 \\
8 & Rejang Lebong & 1.715 & 158,00 & 17.040 & 21.820 \\
9 & Kepahiang & 803,00 & 2.521 & 20.862 & 24.186 \\
\hline & & 8.248 & 11.461 & 79.139 & 98.848 \\
\hline
\end{tabular}

Sumber : BPS Propinsi Bengkulu 2009.

Tabel 7. Produksi Kopi dan Limbah di Propinsi Bengkulu

\begin{tabular}{llccc}
\hline No & Kabupaten & Produksi & Produktifitas & Produksi limbah \\
\hline & & ton/th & ton/th & ton/th \\
\hline 1 & Muko Muko & 927,00 & 0,675 & 474,624 \\
2 & Bengkulu Utara & 10.304 & 0,725 & $5.275,648$ \\
3 & Kota Bengkulu & 12,00 & 0,615 & 6,144 \\
4 & Seluma & 9.904 & 0,750 & $5.070,848$ \\
5 & Bengkulu Selatan & 1.921 & 0,715 & 983,552 \\
6 & Kaur & 3.690 & 0,750 & $1.889,280$ \\
7 & Lebong & 3.431 & 0,675 & $1.756,672$ \\
8 & Rejang Lebong & 12.672 & 0,745 & $6.488,064$ \\
9 & Kepahiang & 16.167 & 0,775 & $8.277,504$ \\
\hline & Jumlah se Propinsi & 59.028 & & $30.222,340$
\end{tabular}

Sumber, BPS Bengkulu 2009 
Tabel 8. Prosentase Berat Biji dan Kulit Kopi dalam $100 \mathrm{~kg}$ setelah Digiling

\begin{tabular}{cccc}
\hline No & Pengamatan ke & \multicolumn{2}{c}{ Buah kopi 100 kg } \\
\cline { 3 - 4 } & & Berat biji (kg) & Berat kulit (kg) \\
\hline 1 & I & 52,0 & 48,0 \\
2 & II & 54,5 & 45,5 \\
3 & III & 46,5 & 53,5 \\
4 & IV & 44,0 & 56,0 \\
5 & V & 47,0 & 53,0 \\
\hline & Jumlah & 244 & 256 \\
& Rata-rata & 48,8 & 51,2 \\
\hline
\end{tabular}

Potensi Substitusi Kompos Terhadap Pupuk an organik

Tabel 9. Perbandingan dan Kesetaraan Hara Beberapa Pupuk Kimia dan Kompos Limbah Kulit Kopi.

\begin{tabular}{llllllll}
\hline Hara & Urea & SP-36 & $\begin{array}{l}\text { Superph } \\
\text { os }\end{array}$ & KCL & NPK Mutiara & $\begin{array}{l}\text { NPK } \\
\text { Phonska }\end{array}$ & $\begin{array}{l}\text { Limbah kulit } \\
\text { kopi }\end{array}$ \\
\hline \multirow{2}{*}{ N } & 46 & & - & - & 16 & 15 & 2,443 \\
& $(18,83)$ & & & & $(6,55)$ & $(6,14)$ & \\
$\mathrm{P}$ & - & 36 & 18 & & 16 & 15 & 0,286 \\
& & $(125,87)$ & $(62,94)$ & & $(55,94)$ & $(52,45)$ & \\
$\mathrm{K}$ & - & - & - & 60 & 16 & 15 & 2,900 \\
& & & & $(20,69)$ & $(5,52)$ & $(5,17)$ & \\
\hline
\end{tabular}

Setelah dikonversi di dapatkan bahwa untuk mensubtitusi nitrogen dari $1 \mathrm{~kg}$ urea dengan nilai nitrogen $46 \% \mathrm{~N}$ maka akan dibutuhkan $18,83 \mathrm{~kg}$ kompos kulit kopi. Kemudian untuk mensubtitusi $1 \mathrm{~kg}$ NPK Mutiara dan NPK Phonska dengan nilai nitrogen $16 \% \mathrm{~N}$ dan $15 \% \mathrm{~N}$ maka akan dibutuhkan masingmasing 6,55 $\mathrm{kg}$ dan 6,14 $\mathrm{kg}$ kompos kulit kopi sebagai besaran nilai substitusinya.
Begitu pula seterusnya terhadap penyetaraan konversi untuk phospor dan kalium.

Jika di kembalikan ke lahan tanaman kopi, penggunaan pupuk urea untuk 1 pohon tanaman kopi dibutuhkan $150 \mathrm{~g}$ urea untuk pemupukan. Dalam 1 tahun dilakukan 2 kali pemupukan sehingga dibutuhkan $300 \mathrm{~g}$ urea/pohon/tahun. Jika dalam 1 ha luasan 
areal tanaman kopi dengan jarak tanam 2,5 $\mathrm{m}$ di dapati 1600 batang pohon tanaman kopi maka akan dibutuhkan urea sebanyak $480 \mathrm{~kg}$ urea/ha/tahun. Nilai penyetaraan kompos kulit kopi terhadap urea dengan konversi ratio 1 : 18 maka akan dibutuhkan massa kompos sebesar 8,640 ton/ha/tahun. Jika Propinsi Bengkulu memiliki luasan areal tanaman kopi seluas 98.848 ha maka akan di butuhkan pupuk kompos kulit kopi sekitar 854.046,720 ton/tahun. Ketersediaan produksi kopi rakyat di Propinsi Bengkulu sebesar 59.028 ton/tahun (table.3) dengan ratio prosentasi biji dan kulit sebesar 48,8\% : 51,2\%, (table.4) maka untuk yang dapat dimanfaatkan sebagai bahan baku kompos yang berasal dari kulit kopi sebanyak 30.222,34 ton/tahun, ini setara dengan 738,323 ton $\mathrm{N} /$ th. Hal ini identik dengan mensubtitusi dengan kesetaraan nilai Urea $(46 \% \mathrm{~N})$ sebesar 339,628 ton/th. Hal ini berarti limbah kulit kopi masih sangat potensial untuk dimanfaatkan sebagai bahan baku pembuatan pupuk kompos sebagai sumber Nitrogen dimana selisih antara kebutuhan pupuk dengan ketersediaan bahan baku asal limbah kulit kopi masih cukup tinggi.

Untuk perhitungan nilai $\mathrm{P}$ dari konversi penyetaraan $1 \mathrm{~kg}$ pupuk superphos dengan kadar $18 \% \quad \mathrm{P}_{2} \mathrm{O}_{5}$ maka akan dibutuhkan sebanyak 62,94 kg kompos kulit kopi. Jika Propinsi Bengkulu memiliki luasan areal tanaman kopi seluas 98.848 ha maka akan di butuhkan pupuk kompos kulit kopi pensubtitusi P sebesar 1.568.915 ton/tahun. Ketersediaan bahan baku kompos yang berasal dari kulit kopi sebanyak 30.222,34 ton/tahun atau setara dengan 86,434 ton P205/th.. Hal ini menunjukan bahwa limbah kulit kopi masih sangat potensial untuk dimanfaatkan sebagai bahan baku pembuatan pupuk kompos sebagai sumber hara Pospor.

Untuk perhitungan nilai $\mathrm{K}$ dari konversi penyetaraan pupuk KCL dengan kadar $60 \%$ $\mathrm{K}_{2} \mathrm{O}$ maka akan dibutuhkan sebanyak 20,69 kg kompos kulit kopi. Dengan luasan areal tanaman kopi yang dimiliki Propinsi Bengkulu yaitu seluas 98.848 ha maka di butuhkan pupuk kompos kulit kopi pensubtitusi hara $\mathrm{K}$ sebesar 711,705,6 ton/tahun.. Oleh karena itu limbah kulit kopi tersebut masih sangat potensial untuk dimanfaatkan sebagai bahan baku pembuatan pupuk kompos sebagai sumber hara K.

\section{SIMPULAN}

Kompos dari bahan limbah kulit kopi memiliki kandungan nutrient sesuai dengan standar SNI 19-7030-2004 tentang standar 
kualitas kompos dan komposisi $80 \quad \%$ limbah kulit kopi $+10 \%$ Pupuk kandang + $10 \%$ dedak padi tanpa gula dan bioaktifator (EM4) memberikan pupuk kompos terbaik dengan kandungan N 2,443\%, Phospor (P2O5) 0,286 \%, Kalium (K2O) 2,9 \% dan nilai $\mathrm{C} / \mathrm{N}$ antara $9,75-15,99 \%$.Panen buah kopi kering giling menghasilkan 51,2 \% limbah kulit kopi dengan potensi sebesar 30.222 ton/tahun dan mensubstitusi urea sebanyak 339,628 ton/tahun, SP-36 sebanyak 31,116 ton/tahun dan $\mathrm{KCl}$ sebanyak 525,826 ton/tahun.

\section{DAFTAR PUSTAKA}

Abdoellah, S dan A.Wardani. 1993. Impact of Cocoa Development on Marginal Land to Farmers Income: A Case in Gunung Kidul Regency, Indonesia. Pelita Perkebunan, no 9. Vol 3. 97 - 104
Afrizon, I.H.Basri, S.D. Daliani dan Robiyanto. 2009. Sistem Integrasi Tanaman Kopi, Kakao dan Ternak Kambing untuk peningkatan pendapatan $20 \%$. Laporan Akhir Tahun. Balai Pengkajian Teknologi Pertanian. Bengkulu

Anonim. 2010. Potensi Pemanfaatan Limbah Perkebunan Menjadi Pupuk Organik. Direktorat Perbenihan Dan Sarana Produksi. Ditjenbun Departemen Pertanian.

Biro Pusat Statistik. 2002. Bengkulu Dalam Angka. Kerjasama Biro Pusat Statistik dengan Badan Perencanaan Pembangunan Daerah Bengkulu 2002.

Direktorat jendral Bina Produksi Perkebunan. 2002. Statistik Perkebunan Kopi Indonesia 2000 2001. Direktorat Jendral Bina Produksi Perkebunan. Departemen Pertanian. Jakarta. 97 hal.

Tisdale, S.L. and W.L. Nelson. 1975. Soil Fertility and Fertilizers. The macMillan Company. 